\title{
GADOLINIUM-153 PRODUCTION AT THE OAK. RIDGE NATIONAL LABORATORY
}

\author{
D. W. Ramey
}

\section{Oak Ridge National Laboratory Operations Division}

P. 0. Box X, Oak Ridge, Tennessee 37831

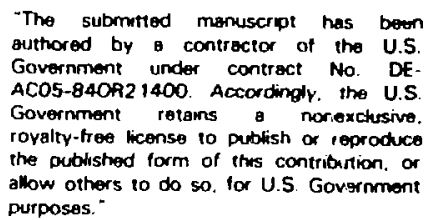

\section{DISCLAIMER}

This report was prepared as an account of work sponsored by an agency of the United States Government. Neither the United States Government nor any agency thereof, nor any of their employees, makes any warranty, express or implied, or assurnes any legal liability or responsibility for the accuracy, completeness, or usefulness of any information, apparatus, product, or process disclosed, or represents that its use would not infringe privately owned rights. Reference herein to any specific commerciai product, process, or service by trade name, trademark. manufacturer, or otherwise does not necessarily constitute or imply its endorsement, recommendation, or favoring by the United States Government or any agency thereof. The views and opinions of authors expressed herein do not necessarily state or reflect those of the United States Government or any agency thereor.

*Based on work performed at the Oak Ridge National Laboratory, operated for the U.S. Department of Energy under contract DE-AC05-840R21400 with the Martin Marietta Energy Systems, Inc. 
D. W. Ramey

\section{Summary}

Gadol inium-153 production at the 0ak Ridge National Laboratory (ORNL) involves the neutron irradiation of natural europium oxide $\left(47.8 \%{ }^{151} \mathrm{Eu}\right.$, $\left.52.2 \%{ }^{153} \mathrm{Eu}\right)$. This target material undergoes a series of neutron captures and radioactive decays to produce the desired ${ }^{153} \mathrm{Gd}$ product. Several undesirable europium isotopes (152 Eu, ${ }^{154} \mathrm{Eu}$, and ${ }^{156} \mathrm{Eu}$ ) are also produced during this irradiation process. Recent technical advances and other improvements in the radiochemical processing of this isotope have allowed ORNL to increase production by more than sevenfold. A newly developed electrochemical process has allowed the separation of the bulk of undesirable europium isotopes and has also affected a more efficient use of high-pressure ion exchange to achieve a final product radiochemical purity $>99.999 \%$. Specific activities $>60 \mathrm{Ci} / \mathrm{g}$ of gadolinium oxide and product specific yields $>2.9 \mathrm{Ci} / \mathrm{g}$ of irradiated europium oxide have been produced. Use of unique glove box manipulators and special equipment designed at ORNL have allowed final source fabrication to keep pace with the increased production rate while minimizing the radiation exposure to operating personnel.

\section{Introduction}

In the late 1960s, a study ${ }^{1}$ at ORNL funded by the National Aeronautical and 
Space Administration (NASA) was initiated to determine the most suitable radionuclide to generate a gamma backscatter signal for applications in an atmospheric density measuring device for the NASA's Mars probe. Gadolinium$153\left(t_{1 / 2}=242 d\right)$ was chosen as the most suitable in view of its energy characteristics, output, half-life, and cost. Two schemes were suggested for the production of $153 \mathrm{Gd}$; one involved the neutron irradiation of ${ }^{152} \mathrm{Gd}$ and the other, the neutron irradiation of $151_{\text {Eu }}$. Irradiation of $151_{\text {Eu was }}$ selected as the most favorable method of producing multicurie quantities of $153 \mathrm{Gd}$. Various purification methods such as co-precipitation with $\mathrm{SrSO}_{4}$ (Jones reductant method), electrochemical purification with a lithium amalgam electrode, and high-pressure ion exchange were investigated. Early production work used the electrochemical process but later gave way to highpressure ion exchange ${ }^{2}$. The more recent development of an electroreduction process $^{3}$ in conjunction with high-pressure ion exchange has combined to form a series of radiochemical processes which now consistently yield a product with only a few parts per million of radiochemical impurities.

At present, ${ }^{153} \mathrm{Gd}$ is one of the most important medical and industrial radioisotopes produced at $0 R N L$. Industrial applications include mass unit absorption gauging, thickness monitoring, and $X$-ray fluorescent applications. This radionuclide is also extremely useful in the field of medicine for the diagnosis and monitoring of osteoporosis, a serious bone disease that affects an estimated 20 million people in the United States. In the medical field, $153 \mathrm{Gd}$ is presently being used as the photon source in dual-photon absorptiometry (DPA) machines which are used to determine bone mineral content in osteoporosis patients. DPA diagnostics have caused a drastic 
increase in the demand for ${ }^{153} \mathrm{Gd}$ in the past several years. In the early 1980s (through 1983), the demand for ${ }^{153} \mathrm{Gd}$ had averaged approximately $30 \mathrm{Ci}$ per year, but by April of 1986, ORNL had outstanding orders for $1,500 \mathrm{Ci}$. To meet the demand for this isotope, ORNL made $25 \%$ more irradiation positions available for ${ }^{153} \mathrm{Gd}$ production; redesigned the reactor target such that a $67 \%$ increase in $\mathrm{Eu}_{2} \mathrm{O}_{3}$ per target was achieved; cut radiochemical process losses in half by improving existing procedures and by using better production data tracking techniques; and, through several research and development efforts, produced an electroreduction process that had the effect of quadrupling the radiochemical processing capacity.

\section{Gadolinium-153 Froduction Details}

Irradiation of Europium-151 The method presently being used for the production of $153 \mathrm{Gd}$ is through the neutron bombardment of natural europium oxide $\left(47.8 \% 15 l_{\mathrm{Eu}}\right.$ and $\left.52.2 \%{ }^{153} \mathrm{Eu}\right)$ powder. During irradiation, ${ }^{15 l_{\mathrm{Eu}}}$ captures a neutron ( $n$, gamma reaction) and produces ${ }^{152} \mathrm{Eu}$ (see Fig. 1). A certain fraction of the ${ }^{152}$ Eu radioactively decays (by beta emission) to $152 \mathrm{Gd}$, which then captures a second neutron to produce the desired ${ }^{153} \mathrm{Gd}$ product. The remaining fraction of the ${ }^{152} \mathrm{Eu}$ undergoes further successive neutron captures to produce heavier europium isotopes. These heavier europium isotopes are undesirable byproducts of the irradiation process. Radiochemical separation processes must be used to separate the europium waste from the gadolinium product.

A standard target rod designed for isotope production in either the High Flux 


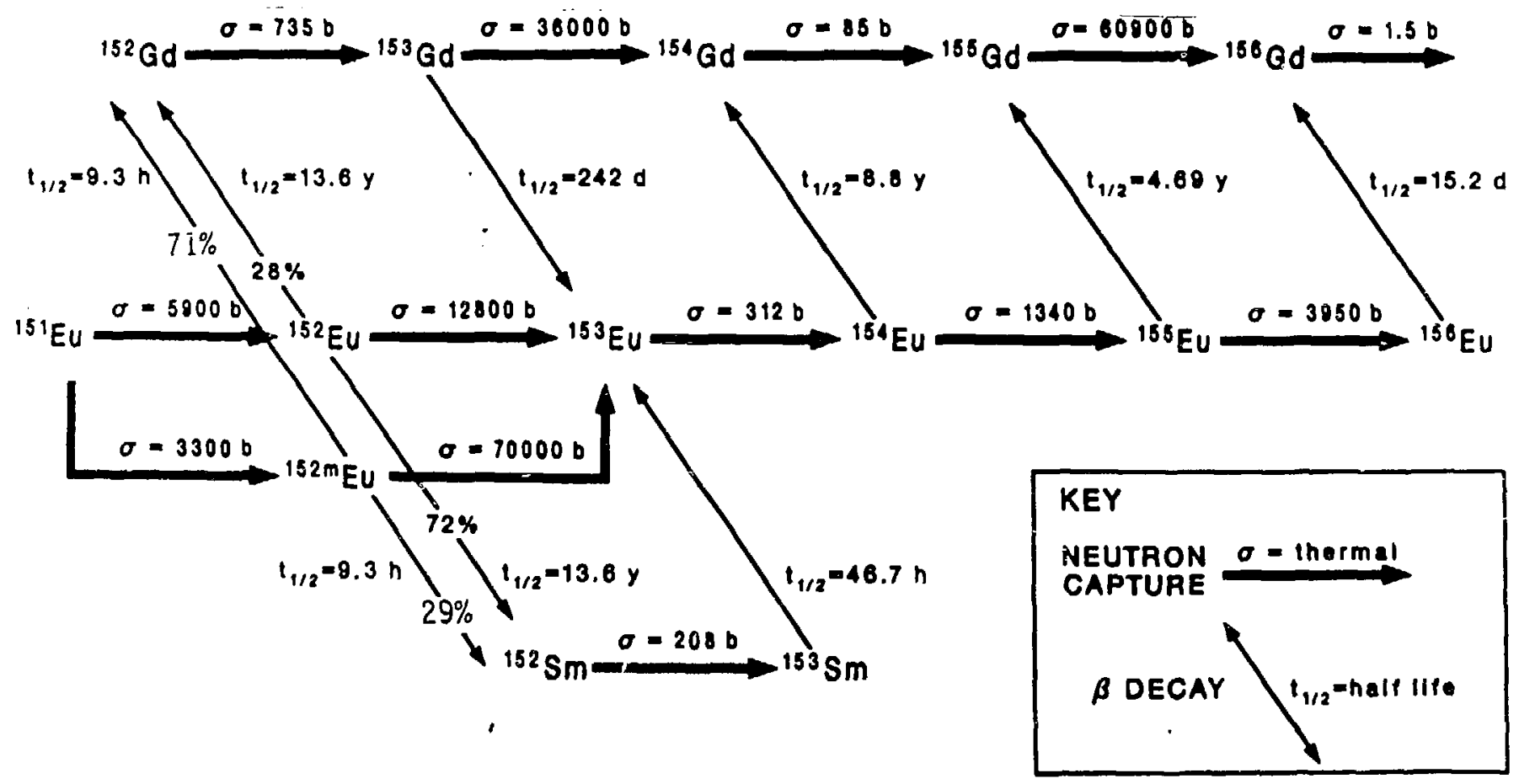

Fig. 1. Nuclear Reaction and Decay Paths in the Production of Gadolinium-153 
Isotope Reactor (HFIR) or the Oak Ridge Research Reactor (ORR) is used for the irradiation of the europium oxide. Target irradiation in the HFIR is performed either in the inner VXFa position (for one cycle) or the outer VXF position (for two cycles). Oxide powder is loaded and flame sealed into quartz tubes $3 \mathrm{~mm}$ ID by $1 \mathrm{~mm}$ wall. Each quartz ampule contains $0.3 \mathrm{~g}$ of the oxide and is approximately $57 \mathrm{~mm}$ long. Five ampules are inserted and centered in each standard target rod, welded, and examined and tested by several quality-control procedures. The total target length including spacers between each ampule is approximately $300 \mathrm{~mm}$ long. Target rods are inserted in the HFIR in multiples of four or in the ORR in multiples of six per irradiation position. These targets will experience an average neutron flux in the range of $2.5 \times 10^{14}$ (ORR) to $3.5 \times 10^{14}$ (HFIR outer VXF) or $8.0 \times$ $10^{14}$ neutrons $/ \mathrm{cm}^{2} \cdot \mathrm{s}$ in the HFIR inner VXF position. Normal irradiation cycles for targets in the ORR, HFIR outer VXF, or the HFIR inner VXF positions are nine, six, or three weeks, respectively.

After irradiation, the series of targets are allowed to "cool-down" in the reactor pool from four to six weeks before being transferred to the hot cell facility for chemical processing. This cool-down period permits the decay for all short-life activation products generated during reactor irradiacion. The decay of short-life isotopes facilitates safer target transport from the reactor to the hot cell facility and, in the case of $156_{\mathrm{Eu}}\left(\mathrm{t}_{1 / 2}=14.7 \mathrm{~d}\right)$ and ${ }^{153} \mathrm{Sm}\left(t_{1 / 2}=46.7 \mathrm{~h}\right)$, reduces radiation background and radiation damage in all phases of chemical processing. 
Radiochemical Processing - Electroreduction Once in the hot cell facility, the irradiated targets are disassembled, and their contents are processed by various wet chemistry techniques to separate the europium waste from the gadolinium product. An outline of all the radiochemical steps used in purifying the gadolinium product is presented below.

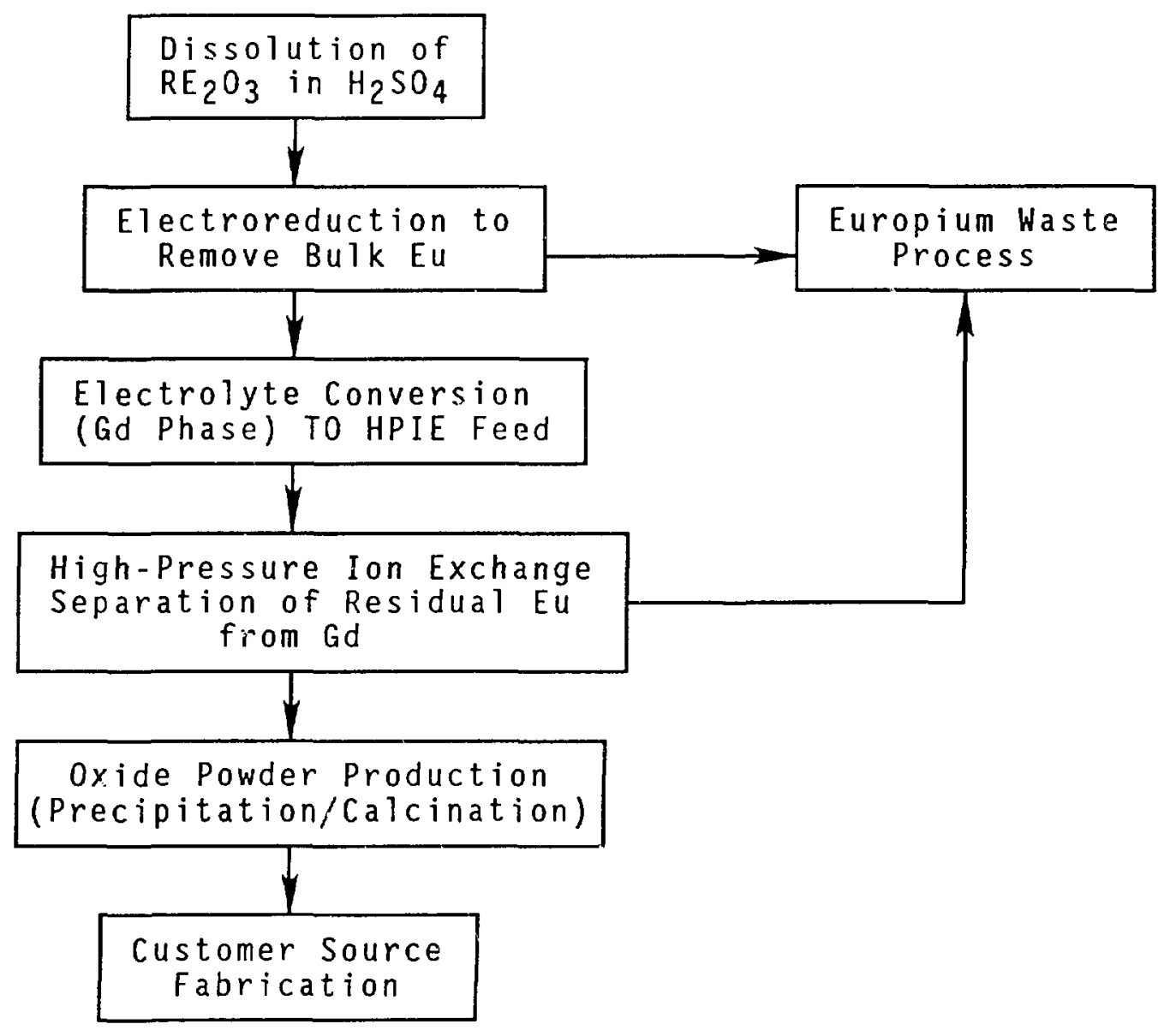

The quartz ampules from the target rods are crushed, and the rare earth oxides $\left(\mathrm{Eu}_{2} \mathrm{O}_{3}\right.$ and $\left.\mathrm{Gd}_{2} \mathrm{O}_{3}\right)$ are dissolved in $1 \mathrm{~N} \mathrm{H}_{2} \mathrm{SO}_{4}$. This sulfuric acid solution is diluted to $0.25 \underline{N}$ in preparation for the electroreduction process. The electroreduction separation technique (developed at ORNL) utilizes the fact that the trivalent EU(III) can be reduced to a lower 
oxidation state at a potential (cell voltage) at which Gd(III) remains unaffected. During electrolysis, the Eu(III) is reduced to the bivalent state, forms an insoluble sulfate, and is precipitated as $\mathrm{EuSO}_{4}$ while leaving behind the Gd(III) still dissolved in the electrolyte. The europium-togadolinium ratio, initially at approximately $17 \mathrm{t} / \mathrm{s}$, is typically reduced by more than two orders of magnitude (a decontamination factor of $10^{2}$ ) in 4 to $5 \mathrm{~h}$ by the electroreduction process. The present electroreduction cell design will allow the processing of from 3 to $7 \mathrm{~g}$ of this europium-gadolinium oxide mixture, with a typical charge being $6 \mathrm{~g}$. Each run is carried out at constant current with a current density of approximately $30 \mathrm{~mA} / \mathrm{cm}^{2}$ and an electrode wetted surface area of $83 \mathrm{~cm}^{2}$. The data in Fig. 2 illustrate the effect of this process on both the europium and gadolinium content of the electrolyte as a function of time. Note that the gadolinium content remains virtually unaffected by this process. The appearance of zinc in the electrolyte is from the electrolytic dissolution of the zinc electrodes used in this process. Further details of the electroreduction process can be found in Reference (3).

Radiochemical Processing - High-Pressure Ion Exchange After the electroreduction step, the gadolinium product is removed from the electrulyte (and separated from the zinc) by a simple ammonium hydroxide precipitation. The resulting gadolinium hydroxide precipitate is dissolved in $8 \mathrm{~N} \mathrm{HNO}_{3}$, evaporated to incipient dryness, and redissolved in $0.05 \mathrm{~N} \mathrm{HNO}_{3}$ in preparation as feed for the high-pressure ion exchange process.

With the bulk of the europium having been removed by the electroreduction 


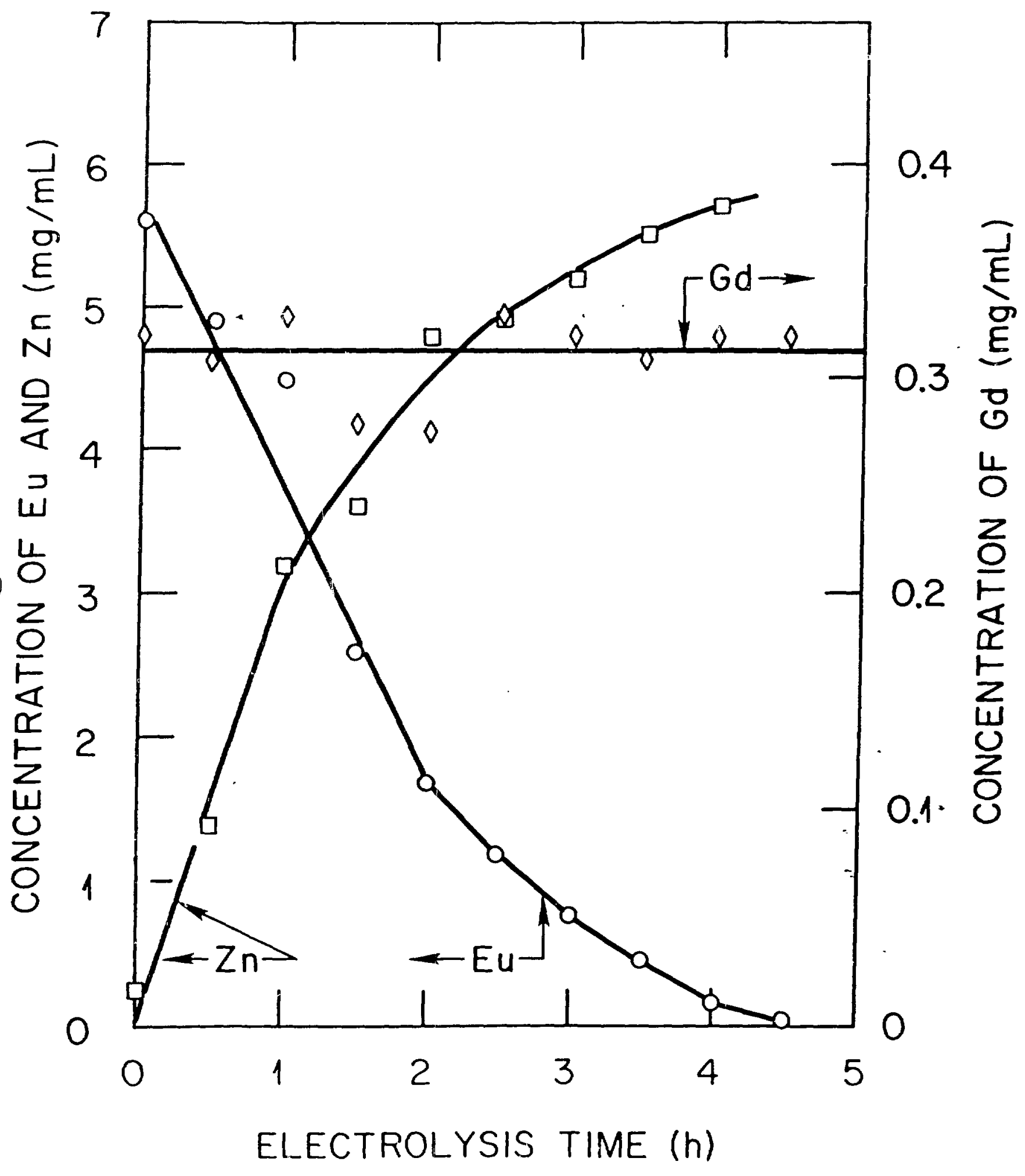

Fig. 2. Performance Characteristics of an Electroreduction Cell 
process, a further separation is achieved by applying high-pressure ion exchange. Final purification is performed on a $1.7-\mathrm{cm}-\mathrm{I}$.D. by $20-\mathrm{cm}-1$ ong column with design features similar to those found in work reported by Brown and Callahan (Reference 2). Column features considered advantageous for hot cell operation include in-situ resin column loading from outside the hot ce11, resin transfers within the column plumbing which allow backwash and repacking of the resin, and a contamination-free high-pressure feed pump located outside the hot cell environment (see Fig. 3). Details of the column's bass = operational modes can be found in Reference (2). With the Dowex-50 type cation-exchange resin, the maximum capacity of this column size is $1.5 \mathrm{~g}$ of rare earth oxides. The column is eluted with $0.15 \underline{M}$ alpha hydroxyisobutyric acid (AHIB) at a $\mathrm{pH}$ of 4.5 . Eluent flow rate is $25 \mathrm{~mL} / \mathrm{m}$ with a column temperature and pressure of $85^{\circ} \mathrm{C}$ and $700 \mathrm{psig}$, respectively. Real-time gross gamma radiation monitoring of the column effluent is used to track the separation of the gadolinium phase from the europium phase. The gadolinium phase will appear in the column effluent in 1 to $2 \mathrm{~h}$ from the time the AHIB is introduced. The gadolinium phase is collected in approximately ten cuts of $100 \mathrm{~mL}$ each. A sample of each $100-\mathrm{mL}$ cut is removed from the hot ce11 and analyzed by gamma spectroscopy. Cuts containing more than the allowable europium are saved and consolidated for a recycle run. Product grade cuts are transferred to the precipitation/calcination facility for final processing. Staring with a 6 -g charge for electroreduction, typically, an ion exchange run will recover approximately $16 \mathrm{Ci}$ of $153 \mathrm{Gd}$ with a radiochemical purityb $>99.99 \%$ (routinely $>99.999 \%$ ) and an additional 1 to $2 \mathrm{Ci}$ which must be recycled. Assuming a europium-to-gadolinium ratio of 0.17 


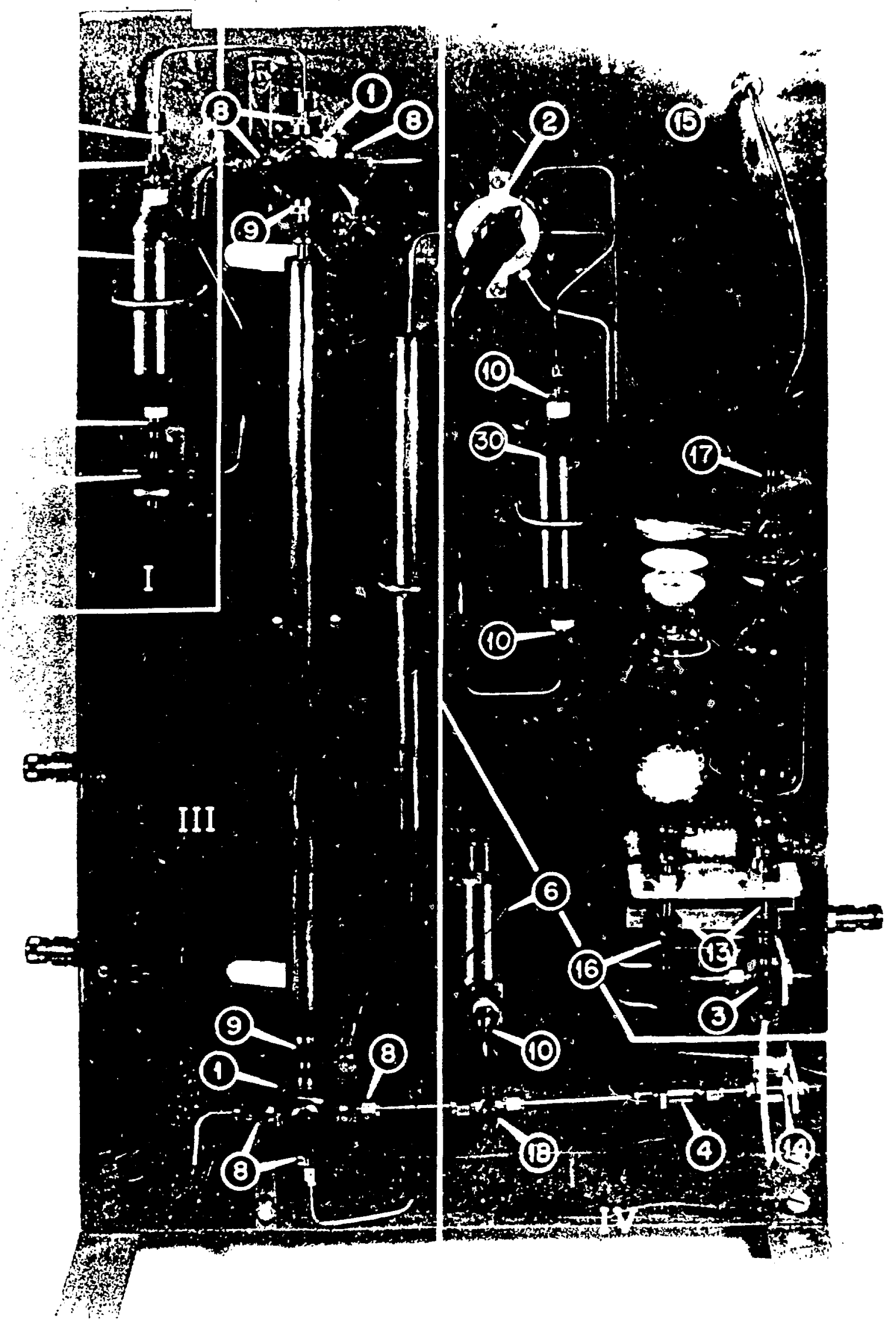

Fig. 3. High-Pressure Ion Exchange Column 
in the feed, after ion exchange this ratio is reduced by approximately four orders of magnitude (a decontamination factor of $10^{4}$ ).

When the end of the gadolinium phase is evident (by a sharp decrease in the radiation reading), product collection is stopped and the column eluent is switched to $0.5 \mathrm{M}$ AHIB at a pH of 6.0 (eluted with approximately 25 column volumes) to hasten the elution of the europium phase. Column stripping of any residual ions is accomplished with $3 \mathrm{M} \mathrm{HNO}_{3}$ to a point where the radiation probe returns to the baseline reading. The resin is then backwashed into a reservoir and repacked in the ion exchange column. This backwashing and repacking procedure is necessary to prevent resin packing with each successive run to the point where ever increasing pressures would be needed to achieve a reasonable flow rate. A typical ion exchange run (including cleaning and reconditioning) is completed in approximately $6 \mathrm{~h}$.

Radiochemical Processing - Oxide Powder Production Product grade material from the high-pressure ion exchange process is transferred to another hot cell where the gadolinium product is concentrated by evaporation, precipitated from the AHIB solution with oxalic acid, and calcined in air at $800^{\circ} \mathrm{C}$ for $5 \mathrm{~h}$, to the oxide $\left(\mathrm{Gd}_{2} \mathrm{O}_{3}\right)$. Typical specific activities of the oxide powder at this point ( 40 to $60 \mathrm{~d}$ out of the reactor) range from 45 to $55 \mathrm{Ci} / \mathrm{g}^{\mathrm{C}}$ which, when normalized to the date the material was pushed from the reactor, yields approximately $60 \mathrm{ci} / \mathrm{g}$. The oxide powder is then stored in a shielded desiccator until ready for customer source fabrication. A typical product-grade gadolinium isotopic abundance analysis, as determined by

C $\mathrm{Ci}$ of $153 \mathrm{Gd} / \mathrm{g}$ of total rare earth oxide 
thermal emission mass spectroscopy, is shown in Table 1.

\begin{tabular}{rc} 
Table 1. Typical & $153_{\mathrm{Gd}}$ product isotopic abundance \\
\hline Isotope & Weight Percent \\
\hline $152_{\mathrm{Gd}}$ & 87.64 \\
$153_{\mathrm{Gd}}$ & 1.76 \\
$154_{\mathrm{Gd}}$ & 6.81 \\
$155_{\mathrm{Gd}}$ & 0.19 \\
$156_{\mathrm{Gd}}$ & 3.57 \\
$157,158,160_{\mathrm{Gd}}$ & 0.03
\end{tabular}

Customer Source Fabrication $0 R \mathrm{RL}^{\prime} \mathrm{s}$ final ${ }^{153} \mathrm{Gd}$ product may be sold as an oxide powder, pressed oxide pellets, or as a chloride solution. By far, the largest product form requested has been for pressed pellets of various sizes for application in DPA machines. The majority of these peliets are $3 \mathrm{~mm}$ in diameter and $1 \mathrm{Ci}$ in activity, with the pellet thickness varying inversely with specific activity. All pellet-pressing operations are performed in a glove box fitted with a set of special manipulators designed at ORNL (see Fig. 4). The oxide powder is weighed out according to the specific customer order, date of shipment, and specific activity of the particular batch of material. The required quantity of powder is loaded into a steel die and cold-pressed at $623,000 \mathrm{kPa}(90,000 \mathrm{psi})$ for $10 \mathrm{~s}$. With multiple-curie orders, the pellets are stack-pressed in sets of three. With the aid of a vacuum handling tool, each pellet is either placed in a customer's metal source capsule or in a plastic vial for shipment to the customer. Before the design and installation of the pellet-pressing manipulator box, hand exposure, using lead-lined gloves, was averaging $1.7 \mathrm{rem} / \mathrm{Ci}$ pressed. Hand exposure now averages approximately $5 \mathrm{mrem} / \mathrm{Ci}{ }^{153} \mathrm{Gd}$ pressed. 


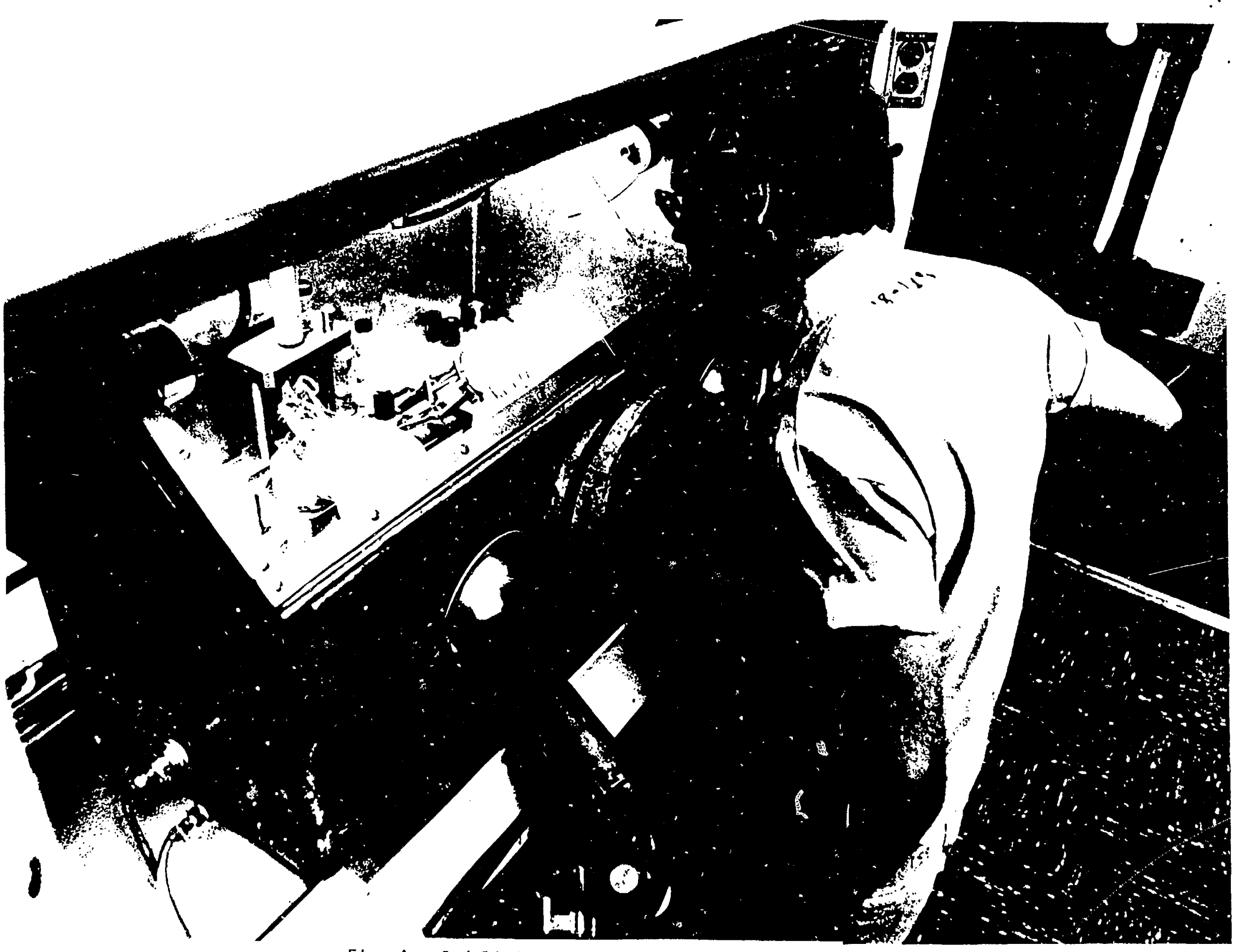

Fig. 4. Gadolinium-153 Pellet Pressing Box 
Europium Waste Processing With every curie of ${ }^{153} \mathrm{Gd}$ produced, there are sizeable quantities of other radionuclides produced during the reactor irradiation (see Table 2). Those radionuclides with half-lives greater than one year will create a long-lived radioactive waste product (16 $\mathrm{Ci} \mathrm{Eu}$ waste/Ci $153 \mathrm{Gd}$ produced) that must be processed into a suitable form for proper disposal. For each curie of ${ }^{153} \mathrm{Gd}$ produced, $0.3 \mathrm{~g}$ of europium waste must be processed. Each gram of waste would produce an estimated radiation field of $450 \mathrm{rad} / \mathrm{h}$ at $1 \mathrm{ft}$.

Table 2. Radionuclide waste products of $153 \mathrm{Gd}$ production at ORNL

\begin{tabular}{ccc}
\hline Radionuclide & Half- 1 ife & Ci Waste/Ci ${ }^{153}$ Gd Produced \\
\hline $153_{\mathrm{Sm}}$ & $46.7 \mathrm{~h}$ & 37 \\
$152_{\mathrm{Eu}}$ & $13.3 \mathrm{y}$ & 12 \\
$154_{\mathrm{Eu}}$ & $8.8 \mathrm{y}$ & 4 \\
$155_{\mathrm{Eu}}$ & $4.7 \mathrm{y}$ & 0.6 \\
$156_{\mathrm{Eu}}$ & $15.2 \mathrm{~d}$ & 10 \\
\hline
\end{tabular}

Several approaches for eliminating the bulk of the europium from aqueous waste straams in the ${ }^{153} \mathrm{Gd}$ process were considered. The most desirable approach would be to remove the europium using a cation resin. Preliminary efforts have produced an ion exchange resin that can, after simple gravity flow contact, be dried and fired to an europium-aluminum titanate and hot pressed into a solid disk. This titanate waste form will offer the most leach-resistent package presently knowr for the europium waste. A short-term solution to the europium waste problem has been to use simple wet chemistry techniques to remove the waste from the aqueous streams of the gadolinium 
process and fire these rare earths to an oxide powder. Temporary storage in welded powder cans in a shielded facility has been proposed until the titanate waste form has been fully developed.

\section{Production Optimization and Alternate Production Methods}

Production 0ptimization The computer code ORIGEN2 ${ }^{4}$ was used to predict the gadolinium and europium isotopic weight fractions, the curies of each radioisotope, and the mass of each isotope as a function of time. Table 3 gives a summary of the isotopes of interest predicted by ORIGEN2d that wouTd be produced from $1 \mathrm{~g}$ of natural europium $\left(47.8 \%{ }^{151} \mathrm{Eu}\right.$ and $\left.52.2 \% 153_{\mathrm{Eu}}\right)$ irradiated for a 21-d cycle in a HFIR inner VXF position. A totà? of $3.14 \mathrm{Ci}$ of $153 \mathrm{Gd}$ is predicted to be produced from this $21-\mathrm{d}$ cycle. The calculated specific activity of $153 \mathrm{Gd}$ at the end of the cycle is $60.10 \mathrm{ci} / \mathrm{g}$ of gadolinium oxide with a maximum specific activity of $60.22 \mathrm{Ci} / \mathrm{g}$ occurring at day 18. Irradiation past 21 days would generate more ${ }^{153} \mathrm{Gd}$ but would also produce more of the heavier gadolinium isotopes (in particular, ${ }^{154} \mathrm{Gd}$ and $156_{\mathrm{Gd}}$ ), while at the same time maintaining a relatively high level of ${ }^{152} \mathrm{Gd}$.

Al1 these reactions will combine to reduce the specific activity, ${ }^{2}$ i.e., $51 \mathrm{Ci} / \mathrm{g}$ at the end of a 44-d irradiation (i.e., two HFIR cycles).

d A discussion of the effective cross sections used for the gadolinium production can be found in Reference (5).

e Maximizing specific activity is important in DPA applications; the higher the specific activity, the less seif-absorption of photons and the longer the life of the source. 
Table 3. Theoretical gadolinium and europium production from $1 \mathrm{~g}$ of natural europium irradiated for $21 \mathrm{~d}$ in a HFIR inner VXF position ${ }^{\star}$.

\begin{tabular}{|c|c|c|c|c|}
\hline \multirow[b]{2}{*}{ Isotope } & \multicolumn{2}{|c|}{ Gadol inium } & \multicolumn{2}{|c|}{ Europium } \\
\hline & Wt. Percent & $\begin{array}{l}\text { Weight } \\
\text { (g) }\end{array}$ & $\begin{array}{c}\text { Weight } \\
(\mathrm{g})\end{array}$ & $\begin{array}{l}\text { Activity } \\
\text { (Ci) }\end{array}$ \\
\hline $\begin{array}{l}151 \\
152 \\
153 \\
154 \\
155 \\
156\end{array}$ & $\begin{array}{r}87.07 \\
1.68 \\
6.95 \\
0.19 \\
2.91\end{array}$ & $\begin{array}{l}4.59 \times 10^{-2} \\
8.89 \times 10^{-4} \\
3.67 \times 10^{-3} \\
1.01 \times 10^{-4} \\
1.54 \times 10^{-3}\end{array}$ & $\begin{array}{l}1.06 \times 10^{-1} \\
2.26 \times 10^{-1} \\
5.43 \times 10^{-1} \\
5.07 \times 10^{-2} \\
4.10 \times 10^{-3} \\
5.97 \times 10^{-4}\end{array}$ & $\begin{array}{c}-- \\
39.1 \\
-- \\
13.7 \\
1.9 \\
32.9\end{array}$ \\
\hline
\end{tabular}

* Assumed average flux of $8.0 \times 10^{14}$ neutrons $/ \mathrm{cm}^{2} \cdot \mathrm{s}$

Actual production data compare quite well with the data predicted by ORIGEN2. Table 4 gives a summary comparison of average production data and those vaiues predicted by the computer code. From a comparison of specific yield data, a recovery efficiency $>90 \%$ for the overali gadolinium separation process is indicated. However, the ORIGEN2 computer code assumes an ideal target for irradiation. No allowance is taken for flux depression caused by target material self-shielding or target shadowing by other targets. In viaw of the large cross sections of some of the isotopes involved in the reaction (see Fig. 1), it is obvious that a less-than-ideal target (oxide powder, $3 \mathrm{~mm}$ in diameter) is being irradiated, and considerable flux depression more than likely takes place within each target. In all probability, a specific yield some-what less than the $3.14 \mathrm{Ci} / \mathrm{g} \mathrm{Eu}_{2} \mathrm{O}_{3}$ predicted by ORIGEN2 is produced during irradiation. Therefore, actual product losses are probably less than the $10 \%$ indicated by the calculated specific yield data. 
Table 4. Average ${ }^{153} \mathrm{Gd}$ production data compared to data generated by the ORIGEN2 computer code

\begin{tabular}{|c|c|c|}
\hline Isotopic Abundance & ORIGEN2 & Production \\
\hline & & \\
\hline \multirow[t]{2}{*}{$\begin{array}{l}152 \mathrm{Gd} \\
153 \mathrm{Gd} \\
154 \mathrm{Gd} \\
155 \mathrm{Gd} \\
156 \mathrm{Gd}\end{array}$} & $\begin{array}{r}87.07 \\
1.68 \\
6.59 \\
0.19 \\
2.91\end{array}$ & $\begin{array}{r}87.64 \\
1.76 \\
6.81 \\
0.19 \\
3.57\end{array}$ \\
\hline & \multicolumn{2}{|c|}{$\mathrm{Ci} / \mathrm{g}$ total $\mathrm{Gd}$} \\
\hline \multirow[t]{2}{*}{ Specific Activity } & 60.10 & 60.00 \\
\hline & \multicolumn{2}{|c|}{ 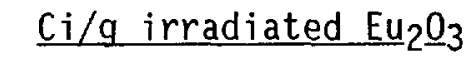 } \\
\hline Specific Yield & 3.14 & 2.90 \\
\hline
\end{tabular}

In view of the data generated by ORIGEN2, a higher specific activity is theoretically possible by terminating the HFIR reactor cycle at day 18 . However, the HFIR cycle is fixed at a nominal $21-d$ period. Also, the gain in specific activity would be hardly noticeable $(0.2 \%$ increase) and would be more than offset by a drop in the specific yield $(>5 \%)$. Fortunately, the present 21-d HFIR cycle is well suited for the type of target that is being used for ${ }^{153} \mathrm{Gd}$ production. Redesign of the target to reduce self-shielding may yield a more optimum irradiation process but, because of the $21-d$ irradiation cycle, would probably produce more of the heavier gadolinium isotopes and thereby reduce the specific activity.

Alternate Production Methods The quantity of $153 \mathrm{Gd}$ produced is directly proportional to the concentration of ${ }^{151} \mathrm{Eu}$ in the target. Experiments at ORNL have shown that normal europium $\left(47.2 \%{ }^{151} \mathrm{EU}\right)$ when enriched to 
approximately $95 \%$ can essentially double the ${ }^{153} \mathrm{Gd}$ production. The cost of enriched europium is approximately $\$ 3900 / \mathrm{g}$ compared to $\$ 2.25 / \mathrm{g}$ for normal europium.

The irradiation of ${ }^{152} \mathrm{Gd}$ is an alternative production method which has several advantages. A shorter irradiation time would be required $(2 \mathrm{~d})$, and the generation of multicurie quantities of the long-lived europium isotopes would be virtually eliminated. Shorter irradiations can be accomplished in the HFIR hydraulic tube facility, where target material will experience an effective flux of $3 \times 10^{15}$ neutrons $/ \mathrm{cm}^{2} \cdot \mathrm{s}$. Shorter target cool-down time before radiochemical processing would al so result from a ${ }^{152} \mathrm{Gd}$ target. This might possibly allow the finished product to be shipped within two weeks from the date of irradiation rather than the six to eight weeks now required (in effect, a $10 \%$ increase in specific activity at date of shipment). The disadvantage of a ${ }^{152} \mathrm{Gd}$ target is the availability of the target material. As pointed out by Kohring ${ }^{5}$, the extraction of gadolinium (>60\% enriched in $152^{G d}$ ) from spent HFIR control plates could be a valuable source of raw material ( $29 \mathrm{~g}$ of gadolinium oxide per plate). It should be noted that with this production scheme the europium waste problem would be transferred to the HFIR coritrol plate processing phase rainer than to the final product radiochemical processing phase. An attractive alternative to the HFIR control places as a source for ${ }^{152} \mathrm{Gd}$ would be the use of spent DPA sources. After a nominal 18 -month 1 ife, these sources contain $>87 \%{ }^{152} \mathrm{Gd}, 0.3 \% 153 \mathrm{Gd}$, and approximately $1.3 \%{ }^{153} \mathrm{Eu}^{f}$. From 1984 through 1987, ORNL has shipped over $1400 \mathrm{Ci}$ of DPA sources or approximately $35 \mathrm{~g}$ of gadolinium oxide. These 
spent sources contain approximately $30 \mathrm{~g}$ of ${ }^{152} \mathrm{Gd}$ oxide which, if recovered, reprocessed, reirradiated, and repurified, would represent a potential of over $2300 \mathrm{Ci}$ of $153 \mathrm{Gd}$ with very 1 ittle europium waste products $\left(2 \times 10^{-3} \mathrm{Ci}\right.$ Eu waste/Ci ${ }^{153}$ Gd produced). The specific yield predicted by ORIGEN2 is approximately $66 \mathrm{Ci}{ }^{153} \mathrm{Gd} / \mathrm{g}$ of $87 \% 152 \mathrm{Gd}$ oxide after a 2 -d irradiation in the HFIR's hydrautic tube facility.

\section{Conclusions}

Gadolinium-153 production capacity at ORNL has surpassed the present demand for this radioisotope. Improved data management and interpretation, removal of bulk europium by a newly developed electroreduction process, efficient application of high-pressure ion exchange, and utilization of an ORNLdesigned pellet-pressing manipulator box all contributed to the success of the gadolinium program. A realistic estimate of the radiochemical processing capacity at $0 R N L$, assuming an average of three rulis per week at $16 \mathrm{Ci} / \mathrm{run}$, would be approximately $2300 \mathrm{Ci}$ per year. Reactor capacity at the HFIR alone (assuming natural europium targets) could supply 1 to $1.2 \mathrm{~kg}$ of irradiated material for processing, which is approximately $14 \%$ more material than is needed for the maximum capacity of our present radiochemical processing facilities. Product specific activities at date of shipment are consistently in the range of 45 to $55 \mathrm{Ci}{ }^{153} \mathrm{Gd} / \mathrm{g}$ of total rare earth oxide with a

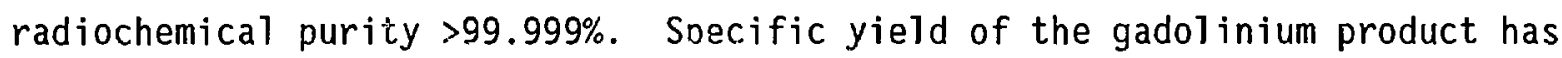
averaged $2.9 \mathrm{ci} / \mathrm{g}$ of irradiated normal europium oxide. Data from the ORIGEN2 computer code show good agreement with production data and indicate that, even though self-shielding probably is occurring, redesign of the standard 
target is not warranted for the production of ${ }^{153} \mathrm{Gd}$. The utilization of spent DPA sources as an europium-free source of ${ }^{152} \mathrm{Gd}$ is an attractive

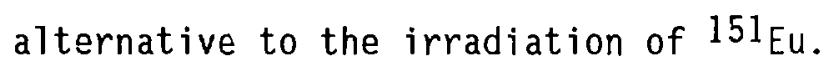

\section{References}

1. E. H. Acree and N. H. Cutshall, Production Study of Gadolinium-153, ORNL/TM-2632, August 1969.

2. L. C. Brown and A. P. Callahan, High-Pressure Ion Exchange Column Design for Remote Hot Cell Operation, ORNL/TM-4583, May 1974.

3. T. C. Quinby, D. W. Ramey, ard M. Petek, Selective Electroreduction of Europium in the Production of Gadolinium-153, Submitted for publication in Radiochimica Acta.

4. A. D. Croff, ORIGEN2 - Revised and Updated Version of the Oak Ridge Isotope Generation and Depletion Code, ORNL-5621, July 1970.

3. M. W. Kohring, Extraction of Gadol inium from High Flux I sotope Reactor Control Plates, ORNL/TM-10394, April 1987. 


\section{Figure Captions}

Fig. 1. Nuclear Reaction and Decay Paths in the Production of Gadolinium-153

Fig. 2. Performance Characteristics of an Electroreduction Cell

Fig. 3. High-Pressure Ion Exchange Column

I - resin backwash reservoir; II - feed loading section; III - ion exchange column; IV - high-pressure eluent inlet

Fig. 4. Gadolinium-153 Pellet Pressing Box 